\title{
CARACTERIZAÇÃO MORFOMÉTRICA E DINÂMICA HÍDRICA NA BACIA HIDROGRÁFICA DO RIO GUAXINDIBA, SÃO FRANCISCO DE ITABAPOANA/RJ
}

\author{
Vinícius dos Santos Reis ${ }^{(\mathrm{a})}$, Leidiana Alonso Alves ${ }^{(\mathrm{b})}$, Mirian Viana Alves ${ }^{(\mathrm{c})}$, José Maria \\ Ribeiro Miro ${ }^{(\mathrm{d})}$
}

(a) Geografia/Instituto Federal Fluminense - Campos/RJ, viniciusreis.ifrj@ gmail.com

(b) Geografia/Universidade Federal Fluminense - Niterói/RJ, leididialves@ hotmail.com

(c) Geografia/Instituto Federal Fluminense - Campos/RJ, mirianvian@outlook.com

(d) Geografia/Universidade Federal Fluminense -Campos/RJ, jmiro@iff.edu.br

\section{EIXO: BACIAS HIDROGRÁFICAS E RECURSOS HÍDRICOS: ANÁLISE, PLANEJAMENTO E GESTÃO}

\begin{abstract}
Resumo
O tema desta pesquisa está associado à análise integrada dos elementos naturais e antrópicos presentes na bacia hidrográfica do rio Guaxindiba. Em sua paisagem destacam-se corpos hídricos lóticos e lênticos, além da Mata do Carvão, inserida na Estação Ecológica Estadual de Guaxindiba. Com o intuito de melhor entender este espaço, o trabalho teve como objetivo: apresentar uma caracterização morfométrica da bacia do rio Guaxindiba, seguido de uma discussão inicial sobre a classificação de seus corpos hídricos. Para isso, o embasamento teórico-metodológico foi pautado no método da Análise Ambiental, pois através dele, é possível compreender a totalidade, funcionalidade e as articulações sistêmicas dos objetos no espaço geográfico. Os resultados mostraram que pode haver erros na classificação de corpos hídricos da bacia, o que traz prejuízo às intervenções para recuperação de áreas degradadas.
\end{abstract}

Palavras chave: Geomorfologia, Análise Ambiental, Recursos hídricos, Índices morfométricos, SRTM.

\section{Introdução}

A Geomorfologia é uma área das Ciências da Terra que estuda as formas de relevo por meio de suas expressões no espaço geográfico, definindo diferentes paisagens. Este objeto faz com que os geomorfólogos sejam capazes de entender os processos de construção e modificação do relevo em diferentes escalas, onde a Morfologia é um instrumento de análise (MARQUES, 2009).

A bacia hidrográfica é um recorte espacial muito utilizado nestas ciências e pode ser definida como a área da superfície do terreno drenada por um rio principal e seus tributários. Ela representa a captação natural da água precipitada que corre superficialmente, está em contato com as águas subterrâneas e converge o escoamento para um único ponto de saída, o exutório. É demarcada pelos divisores de água, a partir da 
definição de um dado ponto no canal principal. Sua delimitação tradicional se dá por meio de uma carta topográfica ou de modo digital, utilizando-se processos automatizados (NOVO, 2008).

Assim, ao delimitar uma bacia hidrográfica poder-se-á realizar classificações através de parâmetros morfométricos, tais como: área, perímetro, coeficiente de compacidade, fator de forma, índice de circularidade, altitudes, densidade de drenagem, além de índices morfométricos dos seus corpos hídricos (CARDOSO et al., 2006).

Atualmente, dados morfométricos podem ser obtidos através de uma estrutura numérica digital que correspondem à distribuição espacial de altitudes da superfície do relevo, chamado de Modelo Digital de Elevação (MDE). Com estes dados é possível gerar curvas de nível por meio de imagens de radar, que devem ser ajustadas às cartas topografias da área (ANDRADE et al., 2009). Assim, para a análise morfológica de uma região, a dinâmica das águas superficiais mostra características importantes para entender e representar o ambiente no qual elas encontram-se inseridas (CARDOSO et al., 2006).

A bacia hidrográfica do rio Guaxindiba está localizada na área de transição entre o relevo montanhoso do cristalino, nos tabuleiros do Grupo Barreiras e na estreita faixa de planície fluviomarinha (GEIGER, 1956). Ela está situada, politicamente, entre os municípios de São Francisco de Itabapoana (maior porção) e Campos dos Goytacazes, ambos pertencentes à região norte do estado do Rio de Janeiro. Na bacia está contida a Estação Ecológica Estadual de Guaxindiba (EEEG), que preserva o maior remanescente contínuo de mata Estacional Semidecidual de todo o estado, também conhecida como "Mata do Carvão", como se vê na Figura 1. O ato de criar a Unidade de Conservação teve como finalidade proteger uma área de 3.270 ha do fragmento de mata e das áreas inundáveis que a circundam, tais como os brejos da Floresta, Cobiça e Expiador, que são contribuintes do rio Guaxindiba (INEA, 2010). 

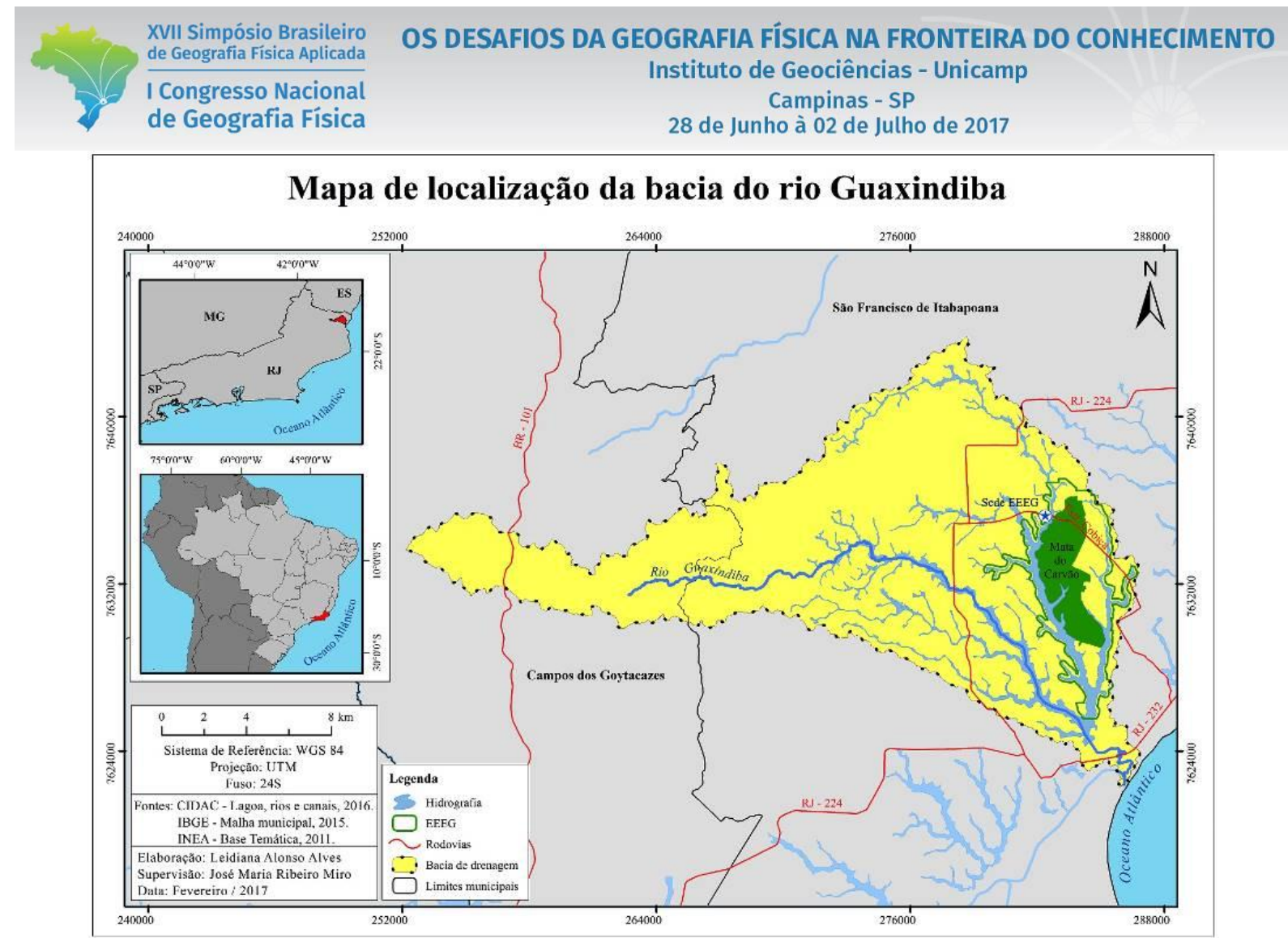

Figura 1 - Mapa de localização da área de estudo

De acordo com o Projeto RADAMBRASIL (1983), as formações florestais sobre os tabuleiros terciários no estado do Rio de Janeiro ocorrem hoje na forma de pequenos fragmentos desde o Rio Grande do Norte até o Rio de Janeiro. Na região Norte Fluminense, a Mata do Carvão (1.053 ha) é o maior remanescente. A denominação de tabuleiros se dá pelo fato da topografia apresentar-se suave ondulada em grandes extensões, não atingindo altitudes superiores a 200 metros (RIZZINI, 1979).

Os sedimentos Cenozóicos (Terciários e Quaternários) não são abundantes na área da Mata Atlântica, situando-se, principalmente, ao longo da orla marítima. Deles se destacam os depósitos arenosos e argiloarenosos de cores vivas do denominado Grupo (Formação) Barreiras, que ocorrem ao longo da costa, dos estados do Rio de Janeiro até o Pará, formando, em grandes extensões, planaltos costeiros de topos aplainados e terminando junto às praias por falésias abruptas, por vezes, com mais de 20 metros de altura, aos quais se atribui o nome de Tabuleiros (SILVA e NASCIMENTO, 2001).

As Florestas Estacionais Semideciduais de Terras Baixas, presentes na área, se caracterizam por perderem de 20 a 50\% de suas folhas na estação seca, que na região Norte Fluminense ocorre entre os meses de maio a outubro (ALVES e MIRO, 2016). Ao fazerem uma descrição dessa formação, Veloso et al. (1991) dizem que nela ainda encontram-se espécies nobres (de valor comercial), como o jequitibá (Cariniana legalis), a peroba-de-campos (Paratecoma peroba), a peroba amarela (Aspidosperma polyneurum), a canela (Tabebuia sp.) e a copaíba (Copaifera lucens). 
Com uma grande variação de espécies, a fauna encontrada na Mata do Carvão contém animais típicos das florestas de regiões costeiras, no qual sua sobrevivência necessita de grandes áreas, inclusive com algumas que constam na lista da extinção do estado do Rio de Janeiro. No entorno do fragmento florestal e, em sua borda, existem áreas úmidas como brejos e trechos florestais paludosos, onde ocorre fauna associada a estes hábitats (INEA, 2010).

O uso da terra na bacia mostra-se bastante concentrado, onde 70,5\% dos pequenos proprietários ocupam apenas $28 \%$ da área, a renda familiar decorrente das atividades agropecuárias, que além de ser baixa é pouco diversificada. Segundo pesquisas recentes junto à população, as maiores reinvindicações das comunidades são: a construção de uma rede de abastecimento de água, melhoria no transporte coletivo e da rede de energia elétrica para as residências. Além disso, não há relatos de ação conjunta para formar uma associação e/ou cooperativa para a organização da produção (Rio Rural, 2011).

Esta pesquisa parte de uma análise da carta topográfica Barra Seca (IBGE, 1968). Nela há corpos hídricos classificados como brejos e pântanos. Contudo, em trabalhos realizados por Alves et al. (2013) e Alves et al. (2015) eles dizem que há corpos hídricos com formas semelhantes, considerados como lagoas nesta região. Desta maneira, o trabalho teve por objetivo apresentar uma caracterização morfométrica da bacia do rio Guaxindiba, seguido de uma discussão inicial sobre a classificação dos seus corpos hídricos.

\section{Metodologia de Trabalho}

O estudo foi realizado tomando-se por base a bacia hidrográfica do rio Guaxindiba. A estrutura da pesquisa se deu a partir de uma revisão bibliográfica em literatura especializada, com o intuito de estabelecer o seu caráter científico. Em seguida foram adquiridos os dados altimétricos do Shuttle Radar Topography Mission (SRTM), composto pelo projeto TOPODATA e disponibilizado, gratuitamente, no site do Instituto Nacional de Pesquisas Espaciais (INPE, 2011); também foram realizadas incursões a campo para a obtenção de dados diretos; análise exploratória das informações geradas e, para a elaboração dos produtos cartográficos, foi utilizado o Software ArcGIS versão 10.2.

Para estabelecer uma classificação dos corpos hídricos da referida bacia, o trabalho contou com um embasamento teórico-metodológico pautado no método da Análise Ambiental. Ele foi atribuído a esta pesquisa devido a sua facilidade para compreender a totalidade, funcionalidade e as articulações sistêmicas no espaço geográfico (CHRISTOFOLLETI, 1999). Está metodologia parte da afirmativa de que os fenômenos espaciais possuem localização, extensão, proximidade, frequência e continuidade nas paisagens. De acordo com Silva (1992) e Câmara \& Medeiros (1998) a metodologia adotada utiliza um conjunto de técnicas e procedimentos que podem ser associados ao uso das geotecnologias, possibilitando 
correlacionar os fenômenos geográficos, tanto no espaço, quanto no tempo. Assim, o método aplicado pode ser entendido como uma série de processos lógicos, que visam integrar dados ambientais georreferenciados em distintas escalas de análise, elevando o nível das informações acerca dos fenômenos representados no espaço geográfico.

\section{Procedimentos Operacionais}

Para caracterizar a bacia do rio Guaxindiba e seus distintos corpos hídricos, primeiramente, ela foi delimitada utilizando-se dados do SRTM da área de estudo. Com a aquisição da Folha 21542 do projeto TOPODATA a imagem digital foi configurada com as seguintes referências espaciais: Sistema de Referência WGS 84, Projeção UTM e Fuso 24S. Desta forma, estabeleceu-se um padrão cartográfico a ser aplicado a todos os mapas aqui utilizados.

O processo de delimitação automática da bacia foi desenvolvido no SIG ArcGIS, junto à ferramenta ArcHydro. Nela, tendo acionado o menu Terriam Preprocessing, seguidos do DEM Manipulation, Fill Sinks, Flow Direction, Flow Accumulation, Stream Definition, Stream Segmentation, Catchment Grid Delineation, Catchment Polygon Processing, Drainage Line Processing, Adjoint Catchment Processing, Drainage Point Processing, Batch Point Generation e Batch Watershed Delineation os divisores de água foram estabelecidos e a bacia gerada.

A análise morfométrica pode ser vista como um relevante instrumento para coletar informações necessárias ao planejamento e gestão dos recursos hídricos de uma bacia, o que possibilita realizar um diagnóstico aprofundado de suas condições ambientais (GOMES et al., 2014). Estudos focados na caracterização da paisagem utilizando parâmetros morfométricos têm demonstrado resultados favoráveis, quando os métodos automáticos são empregados na extração dessas variáveis (VALERIANO, 2008).

Para Junk e Piedade (2015) as planícies de inundação de rios e lagos estão submetidas a processos derivados da distribuição da precipitação maior ou menor. Sazonalmente, os rios mostram oscilação do nível de água com cheias e secas pronunciadas, o que é chamado de "pulso de inundação". Nas áreas costeiras brasileiras a maioria das planícies é inundada por "pulsos de marés", que são relativamente, previsíveis e variáveis em função da variação da maré e geometria do canal na foz (forma e altimetria).

Após delimitar a bacia do rio Guaxindiba obteve-se os seguintes parâmetros físicos ${ }^{1}$ : variação altimétrica do relevo (valores máximo e mínimo), área total de contribuição $(\mathbf{A})$, perímetro $(\mathbf{P})$, maior distância da

\footnotetext{
${ }^{1}$ Os cálculos devem efetuados em metros (m) para comprimentos e metros quadrados $\left(\mathrm{m}^{2}\right)$ para áreas.
} 
desembocadura (L), largura maior (Lm), densidade de drenagem (Dd), coeficiente de compacidade (Kc), fator de forma (F), índice de circularidade (Ic) e índice de sinuosidade (Is).

De acordo com Cardoso et al. (2006), o coeficiente de compacidade (Kc) é um valor que relaciona a forma de uma bacia a um círculo e quanto mais irregular for a bacia, maior será o seu Kc. Para eles, as bacias que apresentam forma circular tem o Kc próximo à unidade e, aquelas com forma alongada, apresentam valor superior a "1". Ainda para os autores, as bacias mais suscetíveis a eventos de enchentes são aquelas que o Kc estiver próximo à unidade, que pode ser determinado pela equação: $\mathrm{Kc}=0,28 * \mathrm{P} / \sqrt{ } \mathrm{A}$.

O Fator de Forma $(\mathrm{F})$ de uma bacia correlaciona seu formato a um retângulo, o que corresponde à razão entre a largura média e o seu comprimento axial, medido da foz até o ponto mais distante da desembocadura. Desta maneira, bacias que apresentarem baixo Fator de Forma estarão menos propensas aos efeitos de enchentes, quando comparadas a outras com a mesma área e maior F. Cardoso et al. (op. cit.) utilizam para o cálculo deste índice a seguinte equação: $\mathrm{F}=\mathrm{A} / \mathrm{L}^{2}$.

Semelhante ao Coeficiente de Compacidade, o Índice de Circularidade (IC) tende a unidade na medida em que a forma da bacia aproxima-se de um círculo e, diminui assim que a forma torna-se alongada. Para o cálculo do IC, Cardoso et al. (op. cit.) dizem que pode ser empregada a equação: $\mathrm{IC}=12,57 * \mathrm{~A} / \mathrm{p}^{2}$.

Para Christofoletti (1980), o estudo da Densidade de Drenagem (Dd) dos sistemas hídricos indica maior ou menor velocidade de circulação da água dentro de uma bacia, indicando a eficiência da drenagem no sistema. O índice correlaciona o somatório dos comprimentos dos cursos hídricos da bacia com sua área e, pode ser calculado pela equação $\mathrm{Dd}=\mathrm{L}_{\mathrm{t}} / \mathrm{A}$, onde " $\mathrm{L}_{\mathrm{t}}$ " é o comprimento total dos canais e " $\mathrm{A}$ " a área da bacia.

O Índice de Sinuosidade (Is) de um rio é a relação entre a distância da desembocadura e a nascente mais distante (equivalente vetorial), medida em linha reta (Lv) e o comprimento do canal principal (L), e pode ser calculado pela fómula Is = L / Lv. Segundo Moura (2013), este índice pode ser utilizado para a determinação da tendência a enchentes, em que os valores menores que 1,40 são considerados Altos; entre 1,40 e 1,75 Moderados; e maiores que 1,75 Baixos, em relação à probabilidade de ocorrência de enchentes nas planícies dos rios, respectivamente.

\section{Resultados e Discussão}

A partir da análise do Mapa Hipsométrico da Bacia do Rio Guaxindiba (Figura 2), observou-se que sua altitude varia entre 0 e 433 metros e que a bacia apresenta desenvolvimento preferencial na direção oesteleste, onde o canal principal tem nascente na região do Cristalino, passando pelos Tabuleiros (com 


\section{OS DESAFIOS DA GEOGRAFIA FÍSICA NA FRONTEIRA DO CONHECIMENTO \\ Instituto de Geociências - Unicamp \\ Campinas - SP \\ 28 de Junho à 02 de Julho de 2017}

altitudes que variam entre 13 e 80 metros), chegando a Planície Costeira antes de desaguar no oceano Atlântico. Além disso, verifica-se que pelas faixas de altitudes estabelecidas, a água do mar pode adentrar ao estuário em até $10 \mathrm{~km}$ horizontalmente (intrusão salina), favorecendo a manutenção do ecossistema de manguezal às margens do canal principal.

Para caracterizar a bacia do rio Guaxindiba utilizou-se parâmetros morfométricos, como demonstrado na Tabela 1. Desta forma, pode-se afirmar que ela apresenta forma alongada, com Coeficiente de Compacidade igual a 2,7542, Fator de Forma de 0,2123 e Índice de Circularidade de 0,1299. Por isso, a bacia pode ser classificada como menos suscetível a eventos de enchentes e inundações, considerando condições normais de precipitação. Sua Densidade de Drenagem é de $1,95 \mathrm{~km} / \mathrm{km}^{2}$, de acordo com a escala de análise utilizada e um Índice de Sinuosidade de 1,62 no canal principal. Valores que a configuram como uma bacia mediana em eficiência da drenagem.

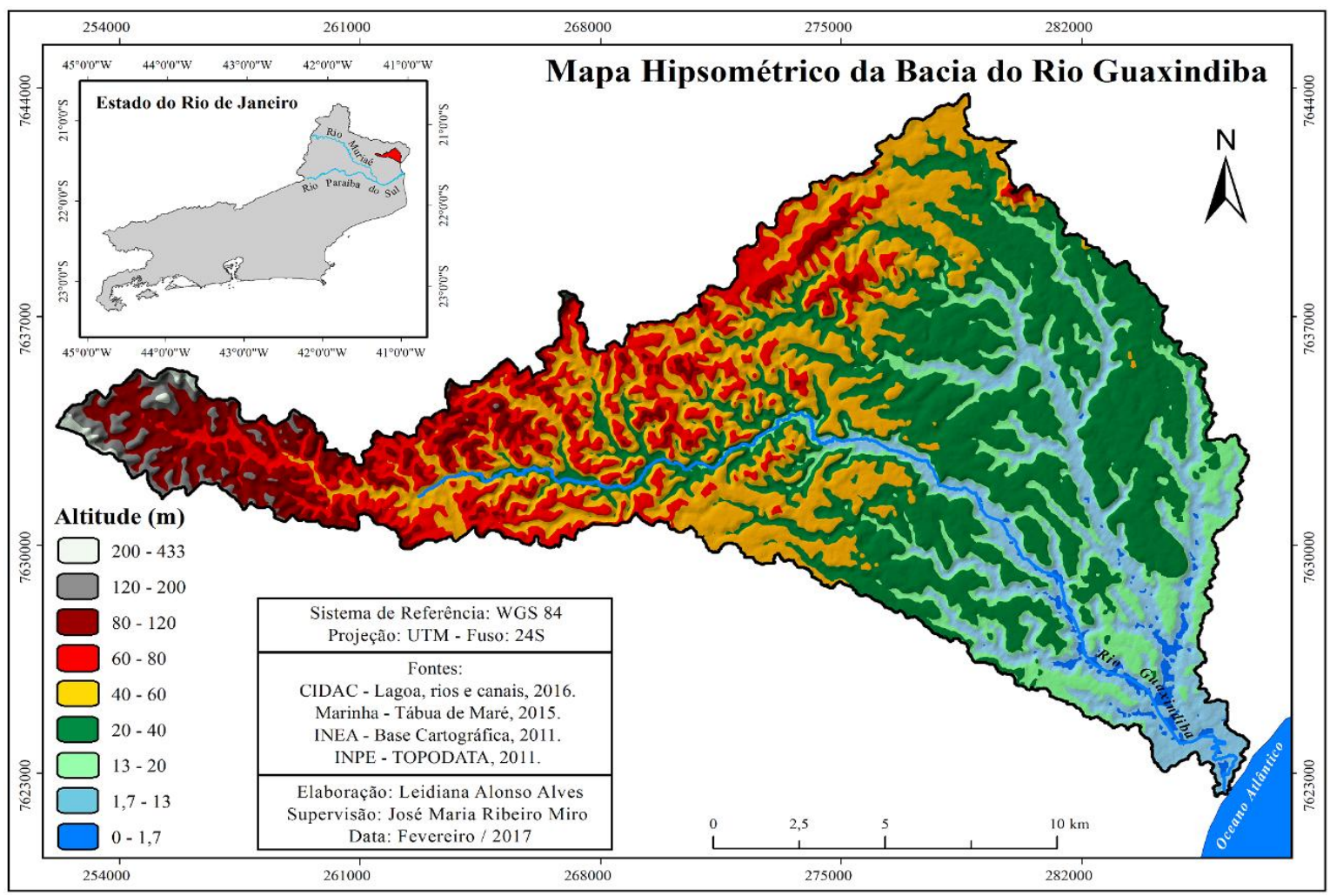

Figura 2 - Altimetria da bacia hidrográfica do rio Guaxindiba

Tabela 1 - Análise morfométrica da bacia do rio Guaxindiba

\begin{tabular}{l|c|c}
\hline Variáveis analisadas & Unidade de medida & Resultados \\
\hline Área de contribuição $(\mathrm{A})$ & $\mathrm{km}^{2}$ & 274,46 \\
\hline Perímetro $(\mathrm{P})$ & $\mathrm{km}$ & 162,96 \\
\hline Coeficiente de compacidade $(\mathrm{Kc})$ & adimensional & 2,7542 \\
\hline
\end{tabular}




\begin{tabular}{l|c|c}
\hline Fator de forma $(\mathrm{F})$ & adimensional & 0,2132 \\
\hline Índice de circularidade (Ic) & adimensional & 0,1299 \\
\hline Altitude máxima & $\mathrm{m}$ & 433 \\
\hline Altitude mínima & $\mathrm{m}$ & 0 \\
\hline Largura maior & $\mathrm{km}$ & 16,79 \\
\hline Maior distância da desembocadura - comprimento $(\mathrm{L})$ & $\mathrm{km}$ & 35,85 \\
\hline Densidade de drenagem (Dd) & $\mathrm{km} / \mathrm{km}^{2}$ & 1,95 \\
\hline Índice de Sinuosidade (Is) & adimensional & 1,62 \\
\hline
\end{tabular}

De acordo com a EMBRAPA (1979), os valores de declividade influenciam na relação entre a precipitação e o deflúvio em bacias hidrográficas, devido ao aumento da velocidade do escoamento superficial nas áreas mais declivosas, o que reduz a possibilidade da infiltração de água no solo, acrescendo, progressivamente, nas áreas mais planas. $\mathrm{Na}$ bacia do rio Guaxindiba (Figura 3), as baixas declividades parecem coincindir com as áreas onde os corpos hídricos tornam-se mais lênticos, desenvolvendo-se ecossistemas de lagoas e brejos.

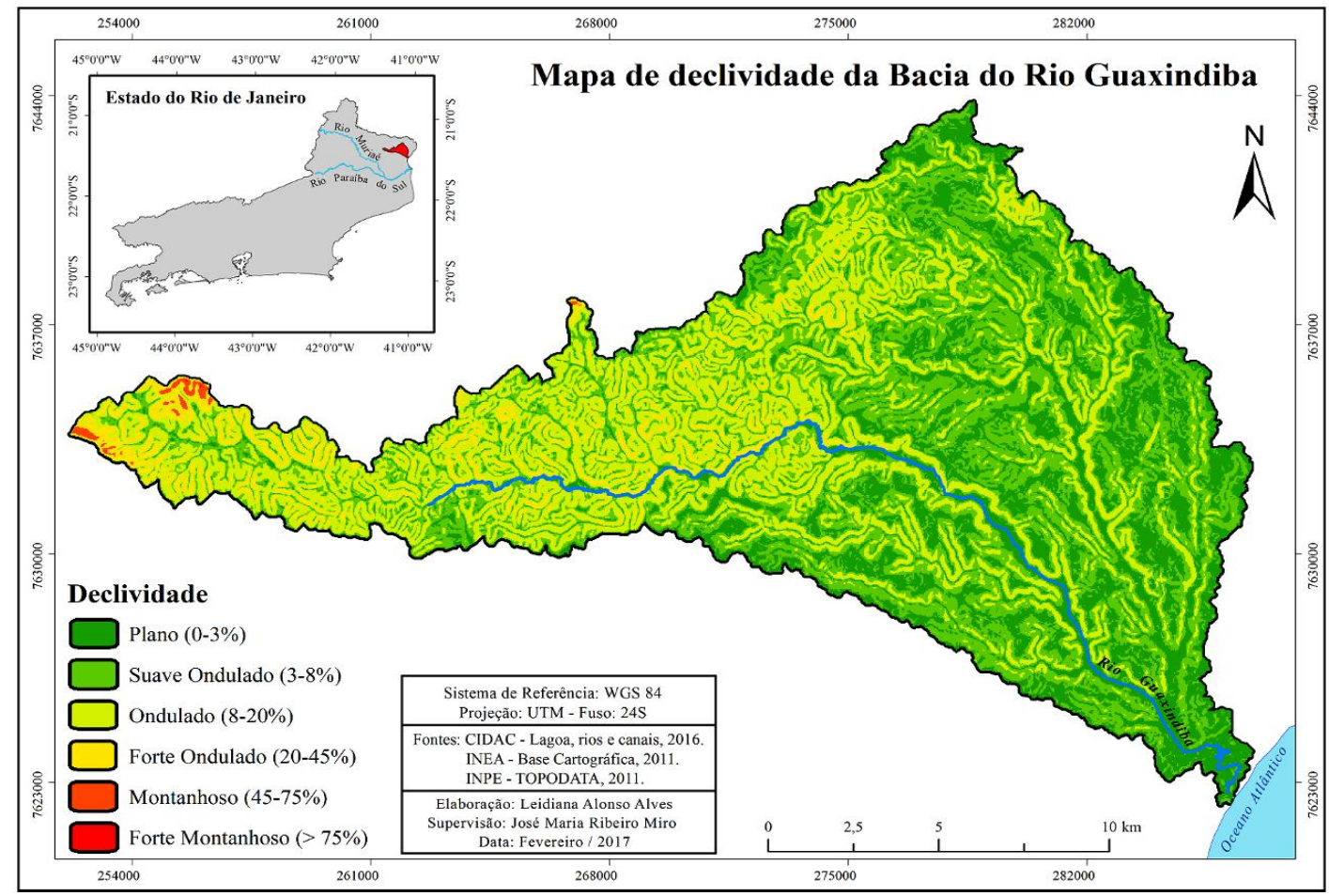

Figura 3 - Declividades no revelo da bacia hidrográfica do rio Guaxindiba

O rio Guaxindiba, canal principal da bacia, é um corpo hídrico de 40,65 km de extensão, contido num vale que se inicia no Cristalino, passando pelos Tabuleiros de Formação Barreiras, com foz no oceano Atlântico (GEIGER, 1956), no município de São Francisco de Itabapoana (Figura 4). O contato entre as águas doce continental e salgada do mar caracteriza um ambiente de transição, propício à existência e 
XVII Simpósio Brasileiro

de Geografia Fisica Aplicada

I Congresso Nacional

de Geografia Física
OS DESAFIOS DA GEOGRAFIA FÍSICA NA FRONTEIRA DO CONHECIMENTO

Instituto de Geociências - Unicamp

Campinas - SP

28 de Junho à 02 de Julho de 2017

manutenção do ecossistema de manguezal (Figura 5). Contudo, seu relevo aplainado, característico de Planície Costeira e as intervenções das obras de engenharia executadas na área faz com que seu curso esteja sugeito a erros de interpretação quanto ao seu comportamento hidrológico e limites entre o que pode ser classificado como rio, lagoa ou brejo.

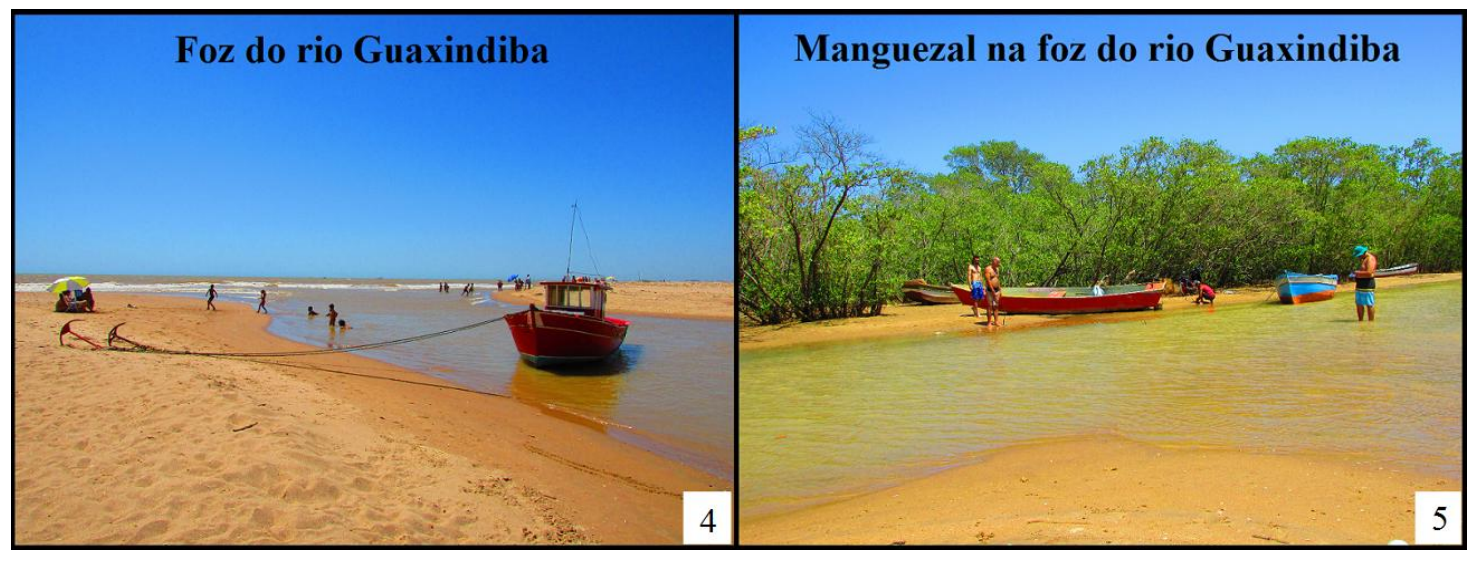

Figuras 4 e 5 - Paisagens do rio Guaxindiba na foz em São Francisco de Itabapoana

Na Carta Topográfica Barra Seca (IBGE, 1968) observam-se os brejos do Espiador, Cobiça e Floresta. Contudo, Alves et al. (2013) e Alves et al. (2015) ao estudarem as lagoas da região Norte Fluminense, tendo como base a Geometria Fractal, atribuíram aos corpos hídricos da região formas semelhantes às apresentadas no curso do rio Guaxindiba. Eles as classificaram como de forma Dendrítica e de gênese relacionada a processos de erosão diferencial nas regiões de Tabuleiros, seguido de barramentos das fozes dos rios por sedimentos da Planície Quaternária.

De acordo com as observações em campo e com o auxílio das geotecnologias, foi possível classificar os corpos lênticos da bacia do rio Guaxindiba como de forma Dendrítica, ou seja, que se assemelham a raízes. Devido a sua abrangência espacial, diversas paisagens puderam ser observadas no campo, tais como: a) uma das extremidades, denominada localmente como lagoa Azul, encontrava-se completamente sem água na estação seca, o que tornou possível uma análise do seu assoalho (Figura 6); b) outra parte do corpo hídrico, encaixado no relevo de Tabuleiro, é demomido pelo IBGE como "Brejo da Floresta" (Figura 7); c) a Figura 8 mostra o pulso de inundação do corpo hídrico alcançando os limites da Formação Barreiras, apontando a variação do espelho d'água; d) nas áreas mais baixas da bacia, observa-se um fragmento preservado de vegetação paludosa conhecida como Mata do Carvão, o que justificou a criação da Estação Ecológica Estadual de Guaxindiba (Figura 9). 


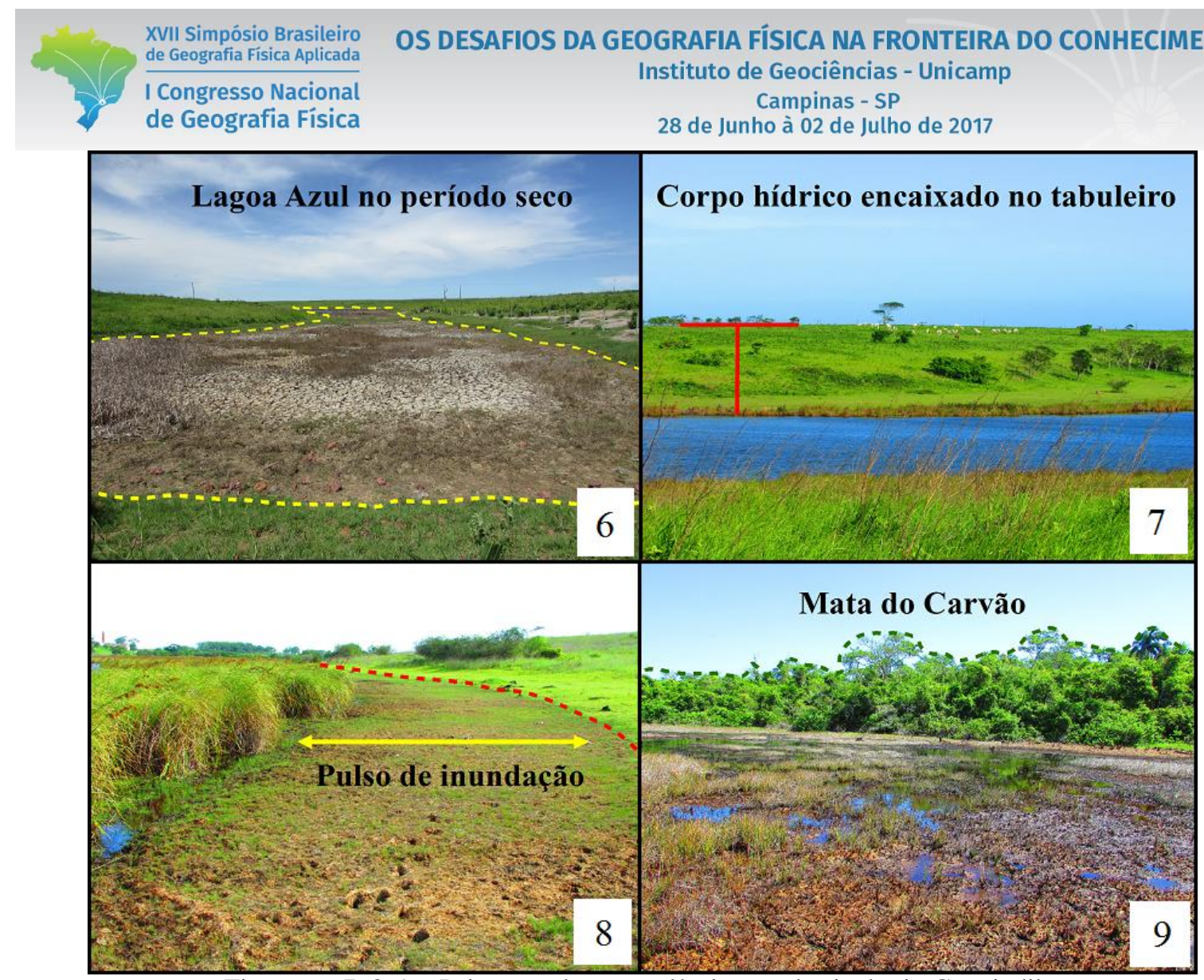

Figuras 6, 7, 8, 9 - Paisagens de corpos lênticos na bacia do rio Guaxindiba

Como ilustrado na Figura 10, foram elaborados cinco perfis transversais ao longo dos corpos lênticos da bacia do rio Guaxindiba, para inferir sobre a sua variação altimétrica e seu encaixe no relevo. Por meio das características morfológicas apresentadas, pode-se entender que há variações suficientes no relevo para carrear materiais das áreas mais altas para o seu interior e que eles mostram depressões semelhantes às encontradas nas mais diversas lagoas da região no norte do estado do Rio de Janeiro. 

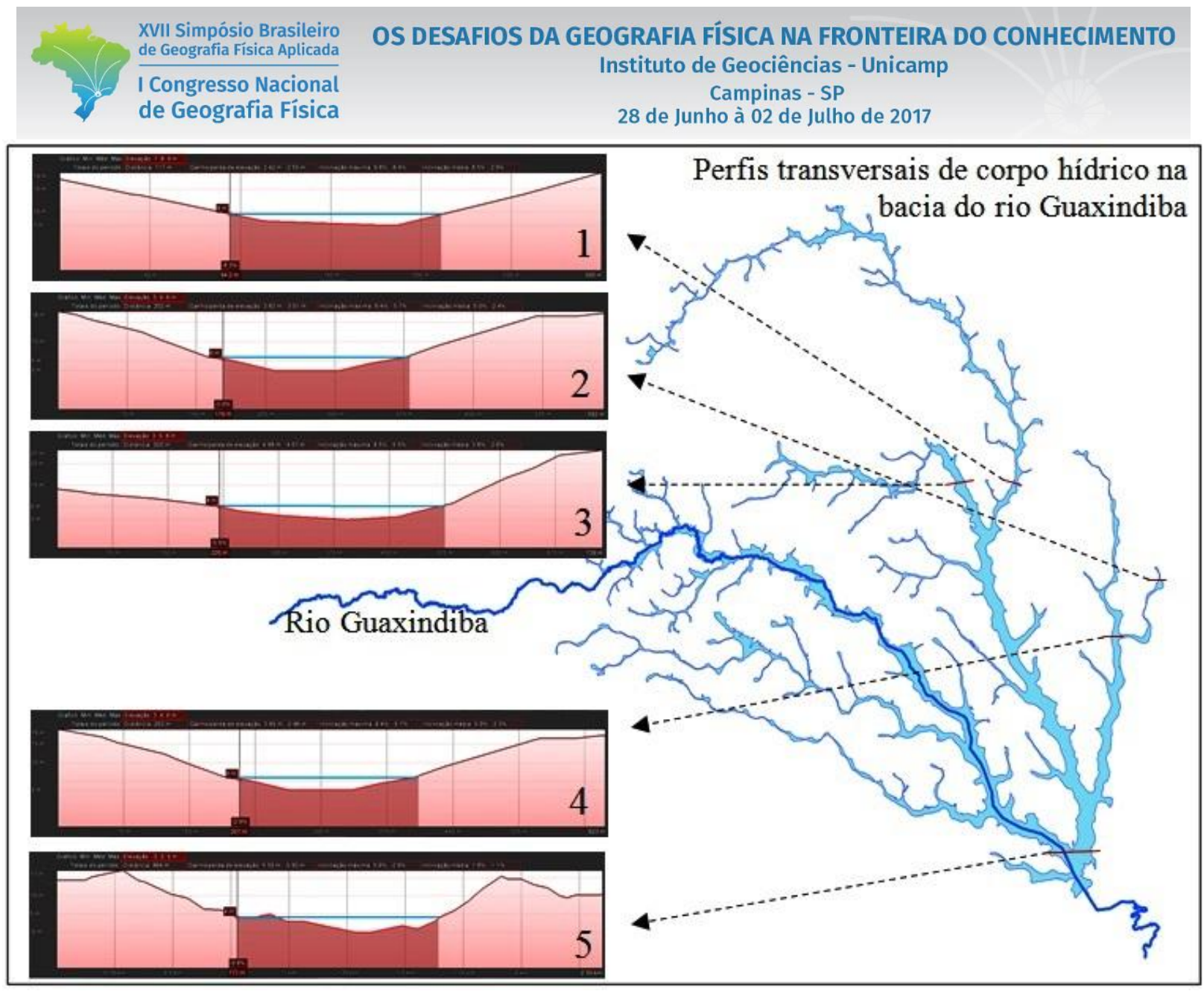

Figura 10 - Perfis transversais na bacia do rio Guaxindiba

\section{Considerações Finais}

A utilização do SRTM e o Software ArcGIS permitiram demarcar a bacia do rio Guaxindiba e seus corpos hídricos e, em seguida, classificá-los morfometricamente. Através da análise dos dados foi possível calcular seus índices de forma e inferir que a bacia é alongada, com áreas mais propensas a inundação onde a declividade do relevo é baixa, levando a pequena dissecação fluvial, o que a torna suscetível a inundações nas áreas de planície. Além disso, observou-se que a intrusão salina, provenientes da água do mar pode adentrar o continente em até $10 \mathrm{~km}$, horizontalmente, à linha de costa.

As análises realizadas a partir dos perfis transversais dos corpos lênticos localizados nas áreas dos Tabuleiros e Planície Costeira da bacia hidrográfica do rio Guaxindiba permitem questionar a classificação do IBGE (Carta Barra Seca de 1968), quando as definem como brejos, pois eles têm profundidade e forma semelhantes às demais lagoas do norte do estado do Rio de Janeiro.

Por fim, assinala-se que obras de engenharia implementadas na área como: canais, diques e represas, que visaram drenar o excedente hídrico da bacia, contribuíram para acentuar os erros de interpretação quando 
se trata da classificação dos seus corpos hídricos. Por isso, sugere-se análise geomorfológica mais criteriosa, para melhor classificar estes corpos hídricos. Esses erros de interpretação podem interferir no desenvolvimento de políticas públicas na bacia, como a recuperação de áreas degradadas promovidas por iniciativas particular ou pública.

\section{Referências Bibliográficas}

ALVES, L. A.; LIMA, V. S.; MIRO, J. M. R.; COELHO, A. L. N. Classificação Geomorfológica das lagoas da Região Hidrográfica do Baixo Paraíba do Sul-RJ. In: SIMPÓSIO BRASILEIRO DE GEOGRAFIA FÍSICA APLICADA, 15., 2013, Vitória, ES. Anais... Vitória, 2013, p. 1200-1208. CD-ROM. ISSN: 2236-5311.

ALVES, L. A.; MIRO, D. O.; LIMA, V. S.; MIRO, J. M. R. O Pantanal Fluminense: um estudo da correlação entre suas lagoas e o relevo da Região Norte do estado do Rio de Janeiro. XV ENCUENTRO DE GEÓGRAFOS DE AMÉRICA LATINA: POR UMA AMÉRICA LATINA UNIDA Y SUSTENTETABLE, 2015, La Habana, Cuba.

ALVES, L. A.; MIRO, J. M. R. Variação temporal dos espelhos d'água das lagoas do Sistema Campelo/RJ. Saarbrücken: Novas Edições Culturais, 2016.

ANDRADE, B. H.; BIAZI, M. S.; OLIVEIRA, P. T. S.; RODRIGUES, D. B. B.; ALVES SOBRINHO, T. Caracterização morfométrica de uma bacia hidrográfica utilizando Sistema de Informações Geográficas. In: XVIII Simpósio Brasileiro de Recursos Hídricos, 2009, Campo Grande. Disponível em: <http://cpan.sites.ufms.br/wpcontent/blogs.dir/99/files/2015/08/Caracteriza\%C3\%A7\%C3\%A3o-morfom\%C3\%A9trica-de-uma-bacia-hidrogr\%C 3\%A1fica-utilizando-Sistema-de-Informa\%C3\%A7\%C3\%B5es-Geogr\%C3\%A1ficas.pdf $>$. Acesso em: 10 fev. 2017.

CÂMARA, G.; MEDEIROS, J. S. Princípios básicos em geoprocessamento. In: ASSAD, E. D.; SANO, E. E. (Org.). Sistemas de informações Geográficas: aplicações na agricultura. Brasília, DF: Embrapa, 1998.

CARDOSO, C. A.; DIAS, H. C. T.; SOARES, C. P. B.; MARTINS, S. V. Caracterização morfométrica da bacia hidrográfica do rio Debossan, Nova Friburgo, RJ. Revista Árvore, Viçosa-MG, v.30, n.2, p. 241-248, 2006.

CHRISTOFOLETTI, A. Modelagem de sistemas ambientais. São Paulo: Editora Edgard Blücher, 1999.

Geomorfologia. São Paulo: Editora Edgard Blücher, 1980.

EMPRESA BRASILEIRA DE PESQUISA AGROPECUÁRIA - EMBRAPA. Serviço Nacional de Levantamento e Conservação de Solos (Rio de Janeiro, RJ). Reunião Técnica de Levantamento de Solos. 10. Súmula. Rio de Janeiro: SNLCS, 1979.

GEIGER, P. P. A Região Setentrional da Baixada Fluminense. In: Revista Brasileira de Geografia. Ano XVIII. n. 1. p. 3-67. Janeiro a Março de 1956.

GOMES, D. D. M.; DUARTE, C. R.; VERÍSSIMO, C. U. V.; LIMAD. R. M. Análise e compartimentação morfométrica da bacia hidrográfica do rio Mundaú - Pernambuco/Alagoas. In: Revista de Geologia, Fortaleza-CE, v. 27, n. 2, p. 167-182, 2014.

INSTITUTO ESTADUAL DO AMBIENTE. Estação Ecológica Estadual de Guaxindiba: plano de manejo. Rio de Janeiro: INEA, 2010.

Base Temática - O Estado do Ambiente: indicadores ambientais do Rio de Janeiro, 2011. Disponível em: <http://www.inea.rj.gov.br/Portal/MegaDropDown/EstudosePublicacoes/Publicaes/EstadodoAmbiente/index.ht m\&lang=PT-BR $>$. Acesso em: 10 set. 2013.

INSTITUTO NACIONAL DE PESQUISAS ESPACIAIS. Topodata: Banco de Dados Geomorfométricos do Brasil, 2011. 
JUNK, W. J.; PIEDADE, M. T. F. Áreas Úmidas (AUs) brasileiras: avanços e conquistas recentes. In: Boletim ABLimno. Rio Claro, v. 41, n. 2, p. 20-24, set. 2015.

MARQUES, J. S. Ciência Geomorfológica. In: GUERRA, A. J. T.; CUNHA, S. B. (Org.). Geomorfologia: uma atualização de bases e conceitos. 9. ed. Rio de Janeiro: Bertrand Brasil, 2009.

MOURA, C. A. Avaliação de tendência a enchentes das bacias hidrográficas do município de Caraguatatuba (SP). In: Revista de Geografia (UFPE), Recife-PE, v. 30, n. 2, p. 123-138, 2013.

NOVO, E. M. L. M. Ambientes Fluviais. In: FLORENZANO, T. G. Geomorfologia: conceitos e tecnologias atuais. São Paulo: Oficina de Textos, 2008.

PROJETO RADAMBRASIL - Levantamento de Recursos Naturais. Geologia, Geomorfologia, Solos, Vegetação e Uso Potencial da Terra. v. 32, Folhas SF 23/24 Rio de Janeiro / Vitória. Rio de Janeiro: IBGE/Ministério das minas e energia - Secretaria Geral, 1983.

RIZZINI, C. T. Tratado de fitogeografia do Brasil. V. 2. São Paulo: Hucitec/Edusp, 1979.

SILVA, G. C.; NASCIMENTO, M. T. Fitossociologia de um remanescente de mata sobre tabuleiros no norte do estado do Rio de Janeiro (Mata do Carvão). In: Revista Brasileira de Botânica. São Paulo, v. 24, n. 1, p. 51-62, mar. 2001.

SILVA, J. X. Geoprocessamento e Análise Ambiental. Revista Brasileira de Geografia. Rio de Janeiro, v. 54 , n. 3. 2 set. 1992.

VALERIANO, M. M. Dados Topográficos. In: FLORENZANO, T. G. Geomorfologia: conceitos e tecnologias atuais. São Paulo: Oficina de Textos, 2008.

VELOSO, H. P.; RANGEL FILHO, A. L. R.; LIMA, J. C. A. Classificação da vegetação brasileira adaptada a um sistema universal. Rio de Janeiro: IBGE, Departamento de Recursos Naturais e Estudos Ambientais, 1991. 